\title{
Role of Very Low Calorie Diet in Type 2 Diabetes Mellitus: A Mini Review
}

\author{
Bondugulapati LNR ${ }^{1 *}$, Farah N Noor ${ }^{2}$, Venkatapur ${ }^{3}$, Patel LP ${ }^{4}$, Kodumuri $V^{5}$, Rahman $\mathbf{M}^{1}$ \\ ${ }^{1}$ Consultant in Diabetes \& Endocrinology, Department of Endocrinology, Maelor Hospital, Wrexham, United Kingdom. \\ ${ }^{2}$ Dietetic assistant, Department of Dietetics, Maelor Hospital, Wrexham, United Kingdom. \\ ${ }^{3}$ Research assistant \& IT support, Ishwar Das Hospital, Kamareddy, India. \\ ${ }^{4}$ Core trainee, Diabetes \& Endocrinology, Maelor Hospital, Wrexham, United Kingdom. \\ ${ }^{5}$ Consultant in Preventive and Interventional Cardiology, Ascension All Saints Hospital, Mount Pleasant, Wisconsin, USA.
}

Received: December 17,2019; Accepted: December 31,2019; Published: January 2,2020

*Corresponding author: Dr. LNR Bondugulapati, Consultant Endocrinologist, MBBS, MRCP (Diab\&Endo), FRCP (Edin), FACE USA. Tel: 0044 1978727107;

E-mail: simmy.omc@gmail.com

\begin{abstract}
Prevalence of Type 2 Diabetes Mellitus (T2DM) is increasing along with obesity rates. Novel approaches are necessary to prevent this deadly pathology and its associated morbidity \& mortality. Recent evidence suggests that very low calorie diet (VLCD) in selective adult T2DM patients, under close supervision, reaps benefits. In this minireview, we have discussed the relevant literature on VLCD in the context of T2DM.
\end{abstract}

\section{Introduction}

Type 2 diabetes mellitus is a metabolic disorder resulting from a combination of insulin resistance and insulin deficiency [1]. It's prevalence has been increasing in epidemic proportions and the global prevalence in adults was quoted to be $8.5 \%$ in 2014 [2]. The first WHO (World Health Organisation) global report on diabetes, which was published in 2016, demonstrated that the number of adults living with diabetes had almost quadrupled since 1980 to 422 million [3]. It is the fifth largest cause of death globally [4]. An aging population, increasing level of obesity in combination with decreased physical activity and poor diet/lifestyle are the major contributing factors [2].

Among the patients with diabetes, 85-95\% have T2DM and it has a huge cost implication on any healthcare system [1]. A study from United Kingdom (UK) estimated that the annual cost of the direct patient care of diabetes in the UK will increase from $£ 9.8$ billion to $£ 16.9$ billion over the next 25 years, lion share of which was attributed to T2DM ( $€ 1$ billion for type 1 diabetes and $£ 8.8$ billion for type 2 diabetes currently) [5].

There is close relationship between T2DM and obesity [6]. For every $1 \mathrm{~kg}$ weight gain, there is a $9 \%$ increase in relative risk of developing T2DM [7]. Metabolic abnormalities associated with T2DM including hyperglycaemia, dyslipidaemia, obstructive sleep apnoea and hypertension are also associated with worsening obesity [8].
Weight reduction plays an important role in the prevention and treatment of T2DM as it improves glycaemic control by reducing the insulin resistance and also has a positive impact on cardiovascular morbidity and mortality [2]. However, long-term non-pharmacologic weight loss interventions for adults with T2DM have shown limited efficacy because of regain of the initial weight loss [2,9]. Henceforth, alternative weight loss strategies that are safe and effective are required [10].

Diets that are generally used to control blood glucose levels include low fat and high unrefined carbohydrate (those which take around $25-30 \%$ of energy from fat and around $50 \%$ of the total energy from unrefined carbohydrate), or low glycaemic index diets (i.e. oats, beans, fruits \& vegetables) usually in conjunction with exercise. In the absence of significant number of long term interventional trials [11] and taking into consideration of the prevalence of T2DM and its potentially serious outcomes, it is important to establish which type of diet, either alone or in combination with other interventions (the addition of exercise, behavioural approaches and alternative treatments), is most effective [1].

A series of recent studies have shown that with a calorie-restricted diet, the reversal of T2 DM is possible in selected patient groups [12]. It is believed that VLCD reduces systemic inflammation and oxidative stress by modulating inflammatory cytokines and adipokines thus resulting in improved beta cell function, decreased hepatic gluconeogenesis and reduction in visceral fat. Henceforth, the usage of VLCD in T2DM patients is progressively becoming popular in view of potential holistic improvement in cardio-metabolic health [13-16]. Indeed, this can be compared with the glycaemic improvement after bariatric surgery [17].

\section{Mechanism of action of VLCD and related evidence}

A very low calorie diet is defined as a diet of less than 800 kilocalories (kcal) per day [18]. In VLCD, intake of fat and carbohydrates is reduced but protein intake is maintained $(0.8$ 
g/kg ideal bodyweight per day) which promotes lipolysis and ketosis while preventing a negative nitrogen balance, thus sparing lean body mass [19]. Fasting plasma glucose levels become normal within days because of a rapid reduction in hepatic fat and normalisation of hepatic insulin sensitivity. Variety of other mechanisms were proposed including reduction in hepatic glycogenolysis and gluconeogenesis. Reduction in pancreatic fat leads to improvement in $\beta$-cell function resulting in restoration of first phase insulin response post-prandially to nondiabetic levels $[11,13,15]$. If the normalization of hepatic insulin sensitivity and $\beta$-cell function could be maintained in the longer term, this could change the entire approach to T2DM management [12] albeit in selected group of patients.

The commonly used VLCD's are commercially available mixedformula diets, containing various amounts of carbohydrate, fat and high quality protein, and they have proven safety for use in patients with T2DM $[19,20]$. In Australia, New Zealand, Singapore and Hong Kong, VLCD products are typically available over the counter and do not require a prescription. Newer VLCD products contain all the essential amino acids, micronutrients thus avoiding related nutritional deficiencies.

The Newcastle Counterpoint study [11] achieved reversal of T2DM with mean weight loss of $15.3 \mathrm{~kg}$ in 11 people with T2DM (duration < 4 years since diagnosis), using a 600 kcal per day lowenergy liquid diet. The normalisation of fasting plasma glucose persisted for up to 3 months after return to normal diet [21]. In addition, acute energy restriction has been shown to improve plasma glucose values and insulin sensitivity even before significant weight loss occurred $[11,22]$.

In a 6 months weight stability study in T2DM in 30 patients following 8 weeks of VLCD, $40 \%$ of participants achieved a fasting blood glucose of $<7 \mathrm{mmol} / \mathrm{L}$ after 6 months of returning to isocaloric diet. The mean weight loss was $2.5 \mathrm{~kg}$ but most of the responders had shorter duration of diabetes and had received structured individualised weight maintenance advice [12].

In DiRECT trial (Diabetes Remission Clinical Trial) which assessed the remission of diabetes with a primary care led weight management programme showed $46 \%$ (n=68) of the participants in the intervention group achieved remission at one year. Around $25 \%(n=36)$ of the participants lost at least $15 \mathrm{~kg}$ of weight. At 24 months, $35.6 \%(53 / 149)$ of those in the intervention group remained in remission compared to $3.4 \%$ (5/149) in the control group. The adjusted mean difference in body weight change in between the control and intervention groups was $-5 \bullet 4 \mathrm{~kg}(95 \%$ CI $-6 \bullet 9$ to $-4 \bullet 0 ; \mathrm{p}<0 \bullet 0001$ ) and in HbA1c was $-4 \bullet 8 \mathrm{mmol} / \mathrm{mol}$. Of those maintaining $\geq 10 \mathrm{~kg}$ weight loss, $64 \%$ (29/45) achieved remission. Serious adverse events were similar at 12 months, but were fewer in intervention than control group in the second year [23].

The short-term effects (i.e. $<6$ months) of VLCD in overweight patients with T2DM were found favourable on hypertension, dyslipidaemia, and HDL Cholesterol [24-26]. However, it is not clear whether this is due to the associated weight loss [27].
Weight regain while readjusting to normal eating after the VLCD can be a problem. This can be influenced by definitive prescription of food type and amount during the food reintroduction and weight maintenance phase [12].

Although bariatric surgery is recommended as a management tool for obese patients with T2 DM, the prospect of bariatric surgery being offered to every eligible individual is minimal because of limited resources [21]. In an observational study, patients with T2 DM who met the eligibility criteria for bariatric surgery were recruited in a 12 weeks programme of very low-calorie diet and had counselling in low to moderate intensity physical activity. The results showed short time weight loss, reduced need for pharmacologic therapy and dramatic improvement in HbA1c particularly in patients with newly diagnosed diabetes [28].

In another study, two groups of subjects aged 18-65 years with BMI $>35 \mathrm{~kg} / \mathrm{m} 2$ followed by HbA1c $6.5-12 \%$ (48-108 $\mathrm{mmol} / \mathrm{mol}$ ) were recruited to analyse the effectiveness between Roux-en-Y gastric bypass and VLCD. The assessment between two groups consisting of individuals who were scheduled to undergo RYGB ( $\mathrm{n}=11)$ or willing to participate in a nonsurgical inpatient VLCD programme $(n=14)$ concluded that Roux-en- $Y$ gastric bypass was not superior to VLCD with regard to early changes in beta cell function in obese subjects with T2DM [29].

In early 70's, there was concern about the modified fasting diets. It was widely believed that rapid weight loss leads to a greater weight gain although an RCT among 204 participants showed that there was no difference of weight regain following a 12-week rapid weight loss programme or a 36 weeks gradual programme at 144 weeks follow-up [30].

Guidelines published in some western countries (e.g. USA) advocate the use of very low calorie/energy diets for weight management, under careful supervision of trained healthcare professionals [31, 32].

The acceptability of VLCD among patients is generally good. Various factors play a role including the potential weight loss, possibility of diabetes remission, and long-term health improvement [33]. In order to maintain weight after successful weight loss, a behavioural change is required. Behavioural therapy and cognitive behaviour therapy (CBT) are potential psychological interventions facilitating better maintenance of weight loss particularly when combined with diet and/or physical activity [34]. A longer duration of the intervention and more frequent clinical contact was associated with an increased effect. However, studies with substantial follow-up (i.e. >2 years) are lacking [2].

\section{Tolerability, cautions and side effects with VLCD}

VLCD is generally well tolerated in majority of patients although due to rapid weight loss and mild ketosis, some patients can experience headache, constipation, hair loss, irritability, lethargy, menstrual irregularities and postural hypotension [35]. Patients can generally handle ketone/acid loads well unless they have advanced kidney disease. There is not much data available with VLCD in patients with background end stage chronic kidney 
disease, severe ischaemic heart disease, pregnancy and breastfeeding [36]. VLCD is deemed unsuitable for patients with active mental health disorders, eating disorders and substance abuse. Caution is advised in patients with established retinopathy given the possibility of short-term flare up of retinopathy when glycaemic control improves rapidly. Patients on drugs with narrow therapeutic index (e.g:warfarin, digoxin) will require dose review. Also, anti-diabetic and antihypertensive medications will need to be reviewed as well along the course of VLCD although there is no agreed consensus on this. Gall stones, exacerbation of gout have also been described occasionally [37].

\section{Conclusion}

Studies with VLCD have shown promising results in adults with T2DM especially when duration of diabetes is shorter. In addition to glycaemic benefit, they may also confer holistic metabolic benefit in terms of lipids and blood pressure. It is important to establish which type of diet, either alone or in combination with other interventions (e.g.: exercise, behavioural approaches), is most effective. Recent systematic review and meta-analysis of randomised controlled trials on educational weight loss interventions in overweight and obese adults with T2DM showed that low-calorie, low-carbohydrate meal replacements or diets, combined with education appear to be the most promising intervention to achieve meaningful weight loss [38].

Further prospective research is required examining a range of interventions to look at the long-term effects and sustainability of the metabolic benefits. If indeed these benefits are sustainable long-term, such dietary restriction could be an alternative approach in selective adult patient groups with T2DM as it can be cost effective with the expected reduction in pill burden, prevention or delay of complications and their associated hospital admissions. VLCD seems to be a promising tool in the armamentarium against T2DM.

\section{References}

1. Moore H, Summerbell C, Hooper L, Cruickshank K, Vyas A, Johnstone P, et al. Dietary advice for treatment of type 2 diabetes mellitus in adults. Cochrane Database Syst Rev. 2004;(3):CD004097.

2. Berk KA, Buijks H, Ozcan B, Van't Spijker A, Busschbach JJ, Sijbrands EJ. The Prevention Of WEight Regain in diabetes type 2 (POWER) study: the effectiveness of adding a combined psychological intervention to a very low calorie diet, design and pilot data of a randomized controlled trial. BMC Public Health. 2012;12:1026. doi: 10.1186/1471-2458-121026

3. World Health Organization. Global Report on Diabetes. 2016.

4. Roglic G and Unwin N. Mortality attributable to diabetes: estimates for the year 2010. Diabetes Res Clin Pract. 2010; 87(1):15-19. doi: 10.1016/j.diabres.2009.10.006

5. National Health Service. Diabetes: cases and costs predicted to rise. 2012.

6. Lai M, Chandrasekera PC, Barnard ND. You are what you eat, or are you? The Challenges of translating high-fat-fed rodents to human obesity and diabetes. Nutr Diabetes. 2014; 4(9): e135. doi: 10.1038/ nutd.2014.30

7. Mokdad AH, Ford ES, Bowman BA, Nelson DE, Engelgau MM, Vinicor F, et al. Diabetes trends in the US: 1990-1998. Diabetes Care. 2000;23(9):1278-1283. doi: 10.2337/diacare.23.9.1278

8. Maggio CA and Pi- Sunyer FX. The prevention and treatment of obesity: application to type 2 diabetes. Diabetes Care. 1997;20(11): 1744-1766. doi: 10.2337/diacare.20.11.1744

9. Norris SL, Zhang X, Avenell A, Gregg E, Brown TJ, Schmid CH, et al. Long-term non-pharmacologic weight loss interventions for adults with type 2 diabetes. Cochrane Database Syst Rev.2005;(2):CD004095.

10. Goday A, Bellido D, Sajoux I, Crujeiras AB, Burguera B, García-Luna PP,et al. Short-term safety, tolerability and efficacy of a very lowcalorie-ketogenic diet interventional weight loss program versus hypocaloric diet in patients with type 2 diabetes mellitus. Nutr Diabetes. 2016;6(9):e230. doi: 10.1038/nutd.2016.36

11. Riccardi G, Capaldo B, Vaccaro O. Functional foods in the management of obesity and type 2 diabetes. Curr Opin Clin Nutr Metab Care. 2005;8(6):630-635

12. Lim EL, Hollingsworth KG, Aribisala BS, Chen MJ, Mathers JC, Taylor R. Reversal of type 2 diabetes: Normalisation of beta-cell function in association with decreased pancreas and liver triacylglycerol. Diabetologia.2011;54(10):2506-2514. doi: 10.1007/s00125-0112204-7

13. Steven S, Hollingsworth KG, Al-Mrabeh A, Avery L, Aribisala B, Caslake $M$, et al. Very low-calorie diet and 6 months of weight stability in type 2 diabetes: pathophysiological changes in responders and nonresponders. Diabetes Care. 2016;39(5):808-815.doi: 10.2337/ dc15-1942

14. Taylor R. Banting Memorial lecture 2012:Reversing the twin cycles of type 2 diabetes. Diabet Med.2013;30(3):267-275.doi: 10.1111/ dme.12039

15. Liu C, Li C, Chen J, Liu Y, Cheng Q, Xiang X, et al. Effects of a very low-calorie diet on insulin sensitivity and insulin secretion in overweight/obese and lean type 2 diabetes patients. Diabetes Metab. 2015;41(6):513-515. doi: 10.1016/j.diabet.2015.09.003

16. Snel M, Jonker JT, Hammer S, Kerpershoek G, Lamb HJ, Meinders AE, et al. Long-term beneficial effect of a 16-week very low-calorie diet on pericardial fat in obese type 2 diabetes mellitus patients. Obesity (Silver Spring). 2012;20(8):1572-1576.doi: 10.1038/oby.2 011.390

17. Knop FK and Taylor R. Mechanism of metabolic advantages after bariatric surgery: It's all gastrointestinal factors versus it's all food restriction. Diabetes Care. 2013;36 Suppl 2:S287-S291. doi: 10.2337/ dcS13-2032

18. NHLBI Obesity Education Initiative Expert Panel on the Identification, Evaluation, and Treatment of Obesity in Adults (US). Clinical guidelines on the identification, evaluation, and treatment of overweight and obesity in adults: the evidence report. 1998. Washington DC: National Institutes of Health.

19. Amatruda JM, Richeson JF, Welle SL, Brodows RG, Lockwood DH. The safety and efficacy of a controlled low-energy ('very-low-calorie') diet in the treatment of non-insulin-dependent diabetes and obesity. Arch Intern Med. 1988;148(4): 873-877.

20. Henry RR and Gumbiner B. Benefits and limitations of very-low-calorie diet therapy in obese NIDDM. Diabetes Care.1991;14(9): 802-823. 
21. Leslie WS, Taylor R, Harris L, Lean MEJ. Weight losses with low-energy formula diets in obese patients with and without type 2 diabetes: systematic review and meta-analysis. Int J Obes (Lond).2017; 41(1):96 -101. doi:10.1038/ijo.2016.175

22. Anderson JW, Kendall CW, Jenkins DJ. Importance of weight management in type 2 diabetes: review with meta-analysis of clinical studies. J Am Coll Nutr. 2003; 22(5): 331-339.

23. Lean MEJ, Leslie WS, Barnes AC, Brosnahan N, Thom G, McCombie L, et al. Durability of a primary care-led weight-management intervention for remission of type 2 diabetes: 2-year results of the DiRECT open-label, cluster-randomised trial. Lancet Diabetes Endocrinol. 2019;7(5):344-355. doi: 10.1016/S2213-8587(19)30068-3

24. Meng Y, Bai H, Wng S, Li Z, Wang Q, Chen L. Efficacy of low carbohydrate diet for type 2 diabetes mellitus management: a systematic review and meta-analysis of randomised controlled trials. Diabetes Res Clin Pract.2017;131:124-131.doi:10.1016/j. diabres.2017. 07.006

25. Huntriss R, Campbell M, Bedwell C. The interpretation and effect of a low-carbohydrate diet in the management of type 2 diabetes: a systematic review and meta-analysis of randomised controlled trials. Eur J Clin Nutr. 2018;72(3):311-325. doi: 10.1038/s41430-017-00194

26. Sainsbury E, Kizirian NV, Partridge SR, Gill T, Colagiuri S, Gibson AA. Effect of dietary carbohydrate restriction on glycemic control in adults with diabetes: A systematic review and meta-analysis. Diabetes Res Clin Pract. 2018;139:239-252.doi: 10.1016/j.diabres. 2018.02.026

27. The association of UK Dietitians. Low carbohydrate diets for the management of Type 2 Diabetes in adults. Policy Statements. 2018.

28. Rothberg AE, McEwen LN, Kraftson AT, Fowler CE, Herman WH. Very-low-energy diet for type 2 diabetes: An underutilized therapy? J Diabetes Complications. 2014;28(4):506-510.doi:10.1016/j. jdiacomp.2014.03.014
29. Jackness C, Karmally W, Febres G, Conwell IM, Ahmed L, Bessler M, et al. Very Low-Calorie Diet Mimics the Early Beneficial Effect of Roux-en-Y Gastric Bypass on Insulin Sensitivity and Beta-Cell Function in Type 2 Diabetic Patients. Diabetes.2013;62(9):3027-3032.doi:10.2337/ db12-1762

30. Purcell K, Sumithrab P, Prendergast LA, Bouniu CJ, Delbridge E, Proietta J. The effect of rate of weight loss on long-term weight management: randomised controlled trial. Lancet Diabetes Endocrinol. 2014;2(12):954-962.

31. The Royal Australian College of General Practitioners. General practice management of type 2 diabetes: 2016-18. East Melbourne, Vic: RACGP, 2016.

32. American Diabetes Association. Standards of medical care in diabetes-2016. J Clin Appl Res Educ. 2016; 39(1).

33. Rehackova L, Araújo-Soares V, Adamson AJ, Steven S, Taylor R, Sniehotta FF. Acceptability of a very-low-energy diet in Type 2 diabetes: patient experiences and behaviour regulation. Diabet Med. 2017;34(11):1554-1567.doi: 10.1111/dme.13426

34. Shaw K, O’Rourke P, Del Mar C, Kenardy J. Psychological interventions for overweight or obesity. Cochrane Database Syst Rev.2005; (2):CD003818.doi: 10.1002/14651858.CD003818.pub2

35. Nestle Health Science. Optifast ${ }^{\circledR} V_{L C D}{ }^{\text {тм }}$ Clinical Treatment Protocol. 2018.

36. Brown A and Taheri S. Very-low-energy diets for weight loss in patients with kidney disease. Journal of Kidney Care. 2018;3(1):1422.doi:10.12968/jokc.2018.3.1.14

37. Mulholland Y, Nicokavoura E, Broom J, Rolland C. Very-low-energy diets and morbidity: a systematic review of longer-term evidence. $\mathrm{Br} \mathrm{J}$ Nutr. 2012;108(5):832-851. doi: 10.1017/S0007114512001924

38. Maula A, Kai J, Woolley AK, Weng S, Dhalwani N, Griffiths FE, et al. Educational weight loss interventions in obese and overweight adults with type 2 diabetes: a systematic review and meta-analysis of randomized controlled trials. Diabet Med. 2019;doi: 10.1111/ dme.14193 